\title{
WHAT MAKES A SUCCESSFUL HELICOPTER PILOT? A FUZZY MULTI-CRITERIA DECISION MAKING APPROACH
}

\author{
Jelena Petrović ${ }^{1}$, Ivan Petrović ${ }^{2}$ \\ ${ }_{1,2}$ University of Defence, Military Academy, Belgrade, Pavla Jurisica Sturma 33, 11 000, Belgrade, Serbia
}

Received 7 July 2021; accepted 20 August 2021

\begin{abstract}
With enlargement of costs of training and hazards, and high responsibility of job, importance of proper selection of pilots is huge. The nature of flight mission can be equally important factor for selection, so as different abilities and test results. On the sample of 50 pilots of different types of helicopter missions (military, police and commercial) without accidents in career, pilots had to make assessment about traits which are high important for successful helicopter pilot, and then make self - assessment based on five point Likert scale. Data were processed by fuzzy - DEMATEL and fuzzy - TOPSIS methods. Quantitative and qualitative differences in assessment of personality traits for successful helicopter pilots between three branches were found.
\end{abstract}

Keywords: military, police, rotary wings, fuzzy-DEMATEL, fuzzy-TOPSIS.

\section{Introduction}

Boyd et al. (2005) report that success of a pilot is mostly dependent on three factors: mental and physical ability, emotional stability, and personal motivation. But, what about personality? How is it possible that the main psychological construct, from the very beginnings of psychology, is missing? What might have happened that created that opinion in the process of selection of the pilots?

The study of pilot personality characteristics has a long and controversial history. Psychologists first measured pilot personality characteristics during World War I, and even at that time there were starkly divergent ideas about which personality characteristics were most important (Rippon \& Manuel, 1918; Dockeray and Isaacs, 1921). During the years of exploration and examination, the consensus is still not reached whether or not personality tests should be included. Some authors are pro (Retzlaff \& Gibertini, 1987, Christen \& Moore, 1989; King et al., 1997; Ellis et al., 2001) and others are contra (Hunter, 1989; Besco, 1994; Hunter \& Burke, 1994; Martinussen, 1996). Those who are pro have tried to answer two different questions. The first is: does pilot's personality differ from general population (Brodsky \& Brodsky, 1967; Fry \& Reinhardt, 1969; Novello \& Youssef, 1974a,b; Ashman \& Tefler, 1983; Lardent, 1991)? The second question is: are there any differences between pilots, according to different parameters? For example, comparison of differences according to: sex (King et al., 1997; McGlohn et al., 1997; Callister et al., 1999; Chappelle et al., 2010), job status: incumbents, applicants and students (Brodsky \& Brodsky, 1967;

${ }^{1}$ Corresponding author: jelena.ilic@va.mod.gov.rs 
Wakcher et al., 2003; Galić et al., 2012), ranks and troop affiliation for military pilots - Navy VS Air Force (Boyd et al., 2005; Chaturvedula \& Joseph, 2007; King et al., 2012), military - civil pilots differences (Meško et al., 2013), type of aircraft: airplane or helicopter (Martinussen, 1996) were conducted.

The aim of this research was to develop a new method, based on small samples (by use of psychologically non-standard fuzzy multi-criteria decision making (MCDM) methods which provide valid results on small samples), for selection of the best fit candidate according to the mission type and to determine whether significant differences in personality traits exist between helicopter pilots flying on different types of missions, since different personality traits can be important in different organizational environments. Military flying in support of combat and/ or humanitarian missions is viewed as an extraordinary profession requiring special traits, talents, and skills. Military pilots are described as courageous, self-disciplined, aggressive, self-confident, interested in high risk activities, intelligent, dexterity oriented, and with a strong motivation to fly (Chappelle et al., 2010). They must fly to the limits of their performance in aerial combat while simultaneously operating radar as well as manipulate with offensive and defensive weapon systems. These pilots need to be self-reliant and capable of high functioning in stressful, multitasking situation (Boyd et al., 2005). According to expert's opinion, an ideal candidate for a military pilot should be extremely emotionally stable, intelligent and conscientious. Moreover, he/she should be a bit extraverted and about average on agreeableness (Galić et al., 2012), and more social oriented, due to the changing trend in mission, from dog fighting to multi-crew mission. Work field of police helicopter pilots is halfway from military to commercial pilots. Their duty is transport of people and goods, sanitary purpose, firefighting, search and rescue, support other police units during interventions, cooperation with other institutions, training service, aerial photography, cargo transport, transport and ejection of paratroopers, traffic control, etc. Commercial pilot's duties are mostly concerning tasks related to transport of people and goods. They are usually freelancers employed by VIP or very rich people or companies. Their engagement might occur occasionally or they can be in the service of some person or company. Their tasks and duties seem to be easiest, more relaxing and, to some degree, they have lower levels of pressure, responsibility and more independence during flights, tasks and decision making process. Commercial helicopter pilots' data show that helicopter pilots also differ significantly from the general population in being higher on the factors of extraversion, agreeableness, and conscientiousness, and lower on the factor of neuroticism. They tend to be more sociable, assertive, energetic; more cooperative, empathic and warm; more organized, methodical and self-disciplined; more relaxed, calm and emotionally stable; flexible, reflective and creative than the general population (Dickens, 2021). Compared to Grice and Katz's (2006) military sample, commercial pilots showed higher levels of agreeableness and openness. The implications of these findings are that commercial pilots are more likely to get along with colleagues and passengers in the line, and be more relaxed and calm under pressure than military pilots. 


\section{Method}

\subsection{Sample}

The sample was high selected and consisted of 50 best helicopter pilots in Serbia, total, without accidents or incidents during career. All pilots had at least 10 years of experience in different types of helicopter and their age varied from 40 to 60 . All pilots were male since there is extremely small number of female pilots in Serbia generally.

\subsection{Procedure}

Participation in this study was voluntary and confidential. All examinees could give up at any time. In the first part of study, ten helicopter pilots had to nominate personality traits which they thought a successful pilot should have. In the second one, data in the form of linguistic variables (which are necessary for evaluation of traits), were gathered by ten helicopter pilots by using the DEMATEL questionnaire. After that, next 30 pilots (ten retired military and police helicopter pilots and ten commercial pilots, respectively) had to make self-assessment on the 27 personality traits. The members of all groups were selected so that all groups were equivalent in terms of relevant factors (level of education and age of experience). Each participant had about 20 minutes for the first two lists, and about 10 minutes for the self - assessment list.

\subsection{Instruments}

The first instrument was the list of personality traits - ten pilots had to nominee personality traits which they thought a successful pilot should have. The respondents created a list of 50 traits and only those which were chosen by all pilots were kept. The second instrument was a DEMATEL-adapted questionnaire for determined mutual influence of 27 remaining (final) traits. The third instrument was self assessment based on a five point Likert scale from $1=$ not very important for successful helicopter pilots (of its own mission) to 5 = very important (adapted to use fuzzyTOPSIS method) on 27 final personality traits. There were 22 (benefit traits) positive and five negative traits (cost traits). Cost traits: impulsive, tense, quarrelsome, selfish and stubborn were inversely scored.

\subsection{Variables}

Independent variables were the type of pilot's mission: commercial, military and police. Dependent variables were 27 personality traits of successful helicopter pilot (ambitious, hardworking, sociable, witty, emotional, impulsive, creative, tense, responsible, determined, careful, intelligent, permissive, obedient, righteous, practical, self - critical, self - confident, cooperative, quarrelsome, selfish, modest, patient, stubborn, persistent, efficient, and brave).

\subsection{Methods and Techniques}

The data were obtained by MATLAB and SPSS 22.0, by fuzzy-DEMATEL and fuzzyTOPSIS (Technique for Order of Preference by Similarity to Ideal Solution) methods. Algorithm of research is shown in Figure 1. 

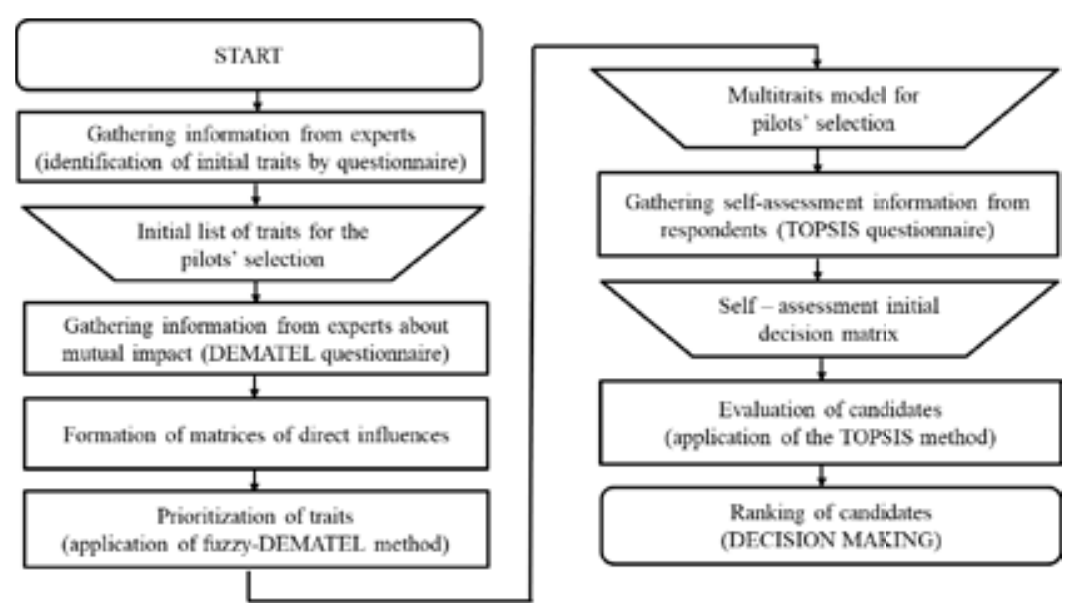

Fig. 1.

Algorithm of Research

\subsection{Fuzzy-MCDM Methods}

The formation and testing of models for ranking candidates for helicopter pilots was performed by using multi-criteria decision making (MCDM) methods. The MCDM methods were often used for solving material and human transportation issues (Dožić, 2019; Bubalo et al., 2021; Tadić et al., 2015; Čokorilo et al., 2010). This type of method is most often used when it is necessary to solve ill-structured problems (Velasquez \& Hester, 2013; Kahraman et al., 2015). These are problems whose solution depends on multiple, usually conflicting (benefit and cost) criteria of different importance weights (multiple dimensions of problem perception), which are difficult to compare (in their original form). Solving such problems involves the introduction of units that allow mutual comparison of criteria (usually using linguistic variables in the form of words or sentences in natural or artificial language) and the calculation of their weights, as well as the selection of the best alternative from a previously prespecified sets of alternatives (Velasquez \& Hester, 2013). The best solution (optimal alternative) is not ideal, it is usually not dominant over other alternatives by all criteria, but in the sum of conditions, it is the best (or least bad) solution (Gavade, 2014). In this paper, the traits' (criteria's) weights were calculated by DEMATEL method, and the ranking of candidates (alternatives) was performed by the TOPSIS method. Due to the relatively small number of respondents (10 by group), fuzzy sets were used, which provided more valid research results.

\subsection{Fuzzy Theory}

Fuzzy sets represent an extension of classical sets theory and their application provides reliability to solve problems based on a small number of often imprecise and uncertain data (Velasquez \& Hester, 2013). There are a lot of types and extensions of fuzzy sets (Kahraman et al., 2015). In this paper, triangular fuzzy sets, which have frequent 
application in research based on a small number of experts' opinions, were applied. This type of sets provides validity of the obtained results in conditions of high level of uncertainty of the subjective experts' opinions (Chou et al., 2012; Devadoss \& Felix, 2013; Kahraman et al., 2014).

Fuzzy set $\tilde{A}$ for each real number $a$ is $\tilde{\mu}(a)$, where is $\tilde{\mu}(a)$ membership function $a$ of triangular fuzzy set $\tilde{A}$ with a value in the interval[0,1]. In a general sense, fuzzy set is represented as follow $\tilde{A}=\{a, \mu(a)\}$ - 'fuzzy sets type 1 (Rajati \& Mendel, 2013).

For two triangular fuzzy set:

$$
\begin{aligned}
& \tilde{A}_{1}=\left(l_{1}, m_{1}, u_{1}\right) \\
& \tilde{A}_{2}=\left(l_{2}, m_{2}, u_{2}\right)
\end{aligned}
$$

Their elementary operations are respectively given as follows (Chang, 1996; Chou, et al., 2012):

1) The addition:

$\tilde{A}_{1} \oplus \tilde{A}_{2}=\left(l_{1}+l_{2}, m_{1}+m_{2}, u_{1}+u_{2}\right)$

2) The subtraction:

$$
\tilde{A}_{1}-\tilde{A}_{2}=\left(l_{1}-u_{2}, m_{1}-m_{2}, u_{1}-l_{2}\right)
$$

3) The multiplication:

$$
\tilde{A}_{1} \otimes \tilde{A}_{2}=\left(l_{1} \times l_{2}, m_{1} \times m_{2}, u_{1} \times u_{2}\right)
$$

4) The division:

$$
\frac{\tilde{A}_{1}}{\tilde{A}_{2}}=\left(\frac{l_{1}}{u_{2}}, \frac{m_{1}}{m_{2}}, \frac{u_{1}}{l_{2}}\right)
$$

5) The multiplication and division operations between the triangular fuzzy set $\tilde{A}_{i}=\left(l_{i}, m_{i}, u_{i}\right)$ and scalar $k$ :

$$
\begin{aligned}
& k \otimes \tilde{A}_{i}=\left(k \times l_{i}, k \times m_{i}, k \times u_{i}\right) \\
& \frac{\tilde{A}_{i}}{k}=\left(\frac{l_{i}}{k}, \frac{m_{i}}{k}, \frac{u_{i}}{k}\right)
\end{aligned}
$$


6) The reciprocal of the triangular fuzzy set $\tilde{A}_{i}=\left(l_{i}, m_{i}, u_{i}\right)$ :

$$
\frac{1}{\tilde{A}_{i}}=\left(\frac{1}{u_{i}}, \frac{1}{m_{i}}, \frac{1}{l_{i}}\right)
$$

7) For any triangular fuzzy set $\tilde{A}_{i}, \sqrt[m]{\tilde{A}_{i}}$ is:

$$
\sqrt[m]{\tilde{A}_{i}}=\left(\sqrt[m]{l_{i}}, \sqrt[m]{m_{i}}, \sqrt[m]{u_{i}}\right)
$$

8) Defuzzification of the triangular fuzzy set $\tilde{A}_{i}$ is (Kahraman et al., 2014):

$$
a_{i}=\frac{l_{i}+4 \times m_{i}+u_{i}}{6}
$$

\subsection{Triangular Fuzzy-DEMATEL Method}

Validation of traits was carried out by using fuzzy-DEMATEL (Decision - Making Trial and Evaluation Laboratory) method. This method is based on the determination of direct and indirect influences between each trait on each trait (Moghaddam et al., 2011; Lin, 2013; Sangaiah et al., 2015; Baykasoğlu, \& Gölcük, 2017). Thus, the degree of direct and indirect influences (no influence, low, medium, high or very high influence) between each trait on other traits was gathered by experts. Based on this data, gathered using the DEMATEL questionnaire, the initial matrix of influence was formed for each expert. The element values per row represent the degree of influence that each trait has on other traits (direct influence), and the element values per column represents the influence that other traits have on each trait (indirect influence). Those matrix provided application of the fuzzy-DEMATEL method.

Procedure of triangular fuzzy-DEMATEL method was done as follows (Wu \& Lee, 2007; Sangaiah et al., 2015; Muhammad \& Cavus, 2017): the average fuzzy set matrix of the influence between traits was obtained by aggregating of the individual $k$ - fuzzy set of influence (after transformation of the linguistic variables in triangular fuzzy set values) as follows:

$$
\tilde{A}=\left[\tilde{a}_{i j}\right]_{n \times n}=\left[\frac{\tilde{a}_{i j}^{(1)} \oplus \tilde{a}_{i j}^{(2)} \oplus \ldots \oplus \tilde{a}_{i j}^{(k)}}{k}\right]_{n \times n}
$$

where is:

$\tilde{A}=\left[\tilde{a}_{i j}\right]_{n \times n}, \tilde{a}_{i j}=\left(l_{i j}, m_{i j}, u_{i j}\right)$ is the triangular fuzzy set element of the non-negative matrix ( $1 \leq i \leq n$-number of columns, $1 \leq j \leq n$ - number of rows), 
$k$ - number of experts (decision makers).

1) The normalized direct-relation matrix is:

$$
\begin{aligned}
& \tilde{X}=\left[\tilde{x}_{i j}\right]_{n \times n}=s \otimes \tilde{A}, \tilde{x}_{i j}=\left(s \times l_{i j}, s \times m_{i j}, s \times u_{i j}\right)=\left(l_{i j}^{x}, m_{i j}^{x}, u_{i j}^{x}\right) \\
& s=1 / \max _{1 \leq i \leq n} \sum_{j=1}^{n} u_{j}
\end{aligned}
$$

2) The total relation matrix is:

$$
\begin{aligned}
& \tilde{T}=\left[\tilde{t}_{i j}\right]_{n \times n}, \tilde{t}_{i j}=\left(l_{i j}^{t}, m_{i j}^{t}, u_{i j}^{t}\right), \\
& l_{i j}^{t}=l_{i j}^{x} \times\left(l_{i j}^{i}-l_{i j}^{x}\right)^{-1}, \\
& m_{i j}^{t}=m_{i j}^{x} \times\left(m_{i j}^{i}-m_{i j}^{x}\right)^{-1}, \\
& u_{i j}^{t}=u_{i j}^{x} \times\left(u_{i j}^{i}-u_{i j}^{x}\right)^{-1}, i, j=1,2, \ldots, n
\end{aligned}
$$

$\tilde{I}=\left[\tilde{i}_{i j}\right]_{n \times n}, i, j=1,2, \ldots, n$ is the triangular fuzzy set identity square matrix with $\tilde{i}_{i j}=\left(l_{i j}^{i}, m_{i j}^{i}, u_{i j}^{i}\right)=(1,1,1), 1 \leq i \leq n, 1 \leq j \leq n, i=j$.

Other values are:

$$
\tilde{i}_{i j}=\left(l_{i j}^{i}, m_{i j}^{i}, u_{i j}^{i}\right)=(0,0,0), 1 \leq i \leq n, 1 \leq j \leq n, i \neq j
$$

3) Defuzzification of the elements of the triangular fuzzy set total relation matrix elements $T_{i j}^{\text {def }}=\left[t_{j}^{\text {def }}\right]_{n \times n}$ was carried out using formula 9.

4) Sum of rows $D_{i}, i=1,2, \ldots, n$ and columns $R_{j}, j=1,2, \ldots, n$ of $T_{i j}^{\text {def }}$ were calculated as follows (Wu \& Lee, 2007; Moghaddam et al., 2011; Hosseini \& Tarokh, 2013):

$$
D_{i}=\sum_{j=1}^{n} t_{j}^{d e f}
$$


$R_{j}=\sum_{i=1}^{n} t_{j}^{d e f}$

5) The weights of traits is (Baykasoğlu, \& Gölcük, 2017):

$$
w_{i}=\sqrt{\left(D_{i}+R_{i}\right)^{2}+\left(D_{i}-R_{i}\right)^{2}}
$$

6) The normalized weights of traits is (Baykasoğlu, \& Gölcük, 2017):

$$
W_{i}=\frac{w_{i}}{\sum_{i=1}^{n} w_{i}}, i=1, \ldots, n \text { - number of traits. }
$$

\subsection{Triangular Fuzzy -TOPSIS Method}

The selection model was tested by TOPSIS (Technique for Order of Preference by Similarity to Ideal Solution) method (Hwang and Yoon, 1981; Junior et al., 2014; Sangaiah et al., 2015). This method is based on the ranking of alternatives in relation to the ideal and negative ideal solution (Junior et al., 2014; Sangaiah et al., 2015). The ideal solution maximizes the traits of benefit type and minimizes traits of cost type, and the negative ideal solution maximizes traits of cost type and minimizes the traits of benefit type. The ranking of candidates is carried out by the closest to the ideal and the farthest from the negative ideal alternative (Hwang and Yoon, 1981; Junior et al., 2014). The following procedure of the application of fuzzy-TOPSIS method was done (Hwang and Yoon, 1981; Shih, 2008; Sangaiah et al., 2015):

1) Individual $m$ - decision vectors with the elements in form of linguistic variables was created from the list of the candidates (10 candidates).

2) The initial decision matrix was obtained using the individual $m$ - decision vectors ( $m$ $=10$ candidates) with the elements in the form of fuzzy set:

$\tilde{F}=\left[\tilde{f}_{i j}\right]_{n \times m}, 1 \leq i \leq n, 1 \leq j \leq m$

$n$ - Number of traits,

$m$ - Number of candidates.

$\tilde{f}_{i j}=\left(f_{i j 1}, f_{i j 2}, f_{i j 3}\right)$ - Fuzzy set element of the initial decision matrix $1 \leq i \leq n, 1 \leq j \leq m$

3) The normalized decision matrix is: 


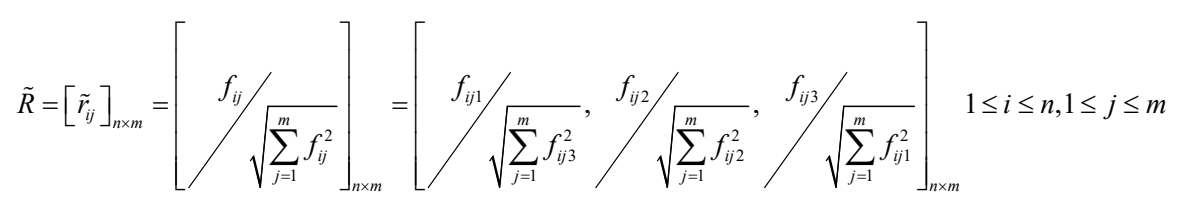

4) The weighted normalized decision matrix is:

$\widetilde{V}=\left[\widetilde{v}_{i j}\right]_{n \times m}=\left[\left(v_{j 1}, v_{j 2}, v_{j 3}\right)\right]_{n \times m}, \widetilde{v}_{j}=W_{i} \otimes \widetilde{r}_{j}$

5) The defuzzificated weighted normalized decision matrix $V_{\ddot{j}}^{d e f}=\left[v_{j}^{d e f}\right]_{n \times m}$ is obtained using formula 9.

6) The positive and negative ideal solutions are respectively calculated:

$V_{j}^{+}=\left\{\left(\max v_{i j}^{\text {def }}, i \in G\right),\left(\min v_{i j}^{\text {def }}, i \in G^{-}\right), j=1, \ldots, m\right\}=\left\{v_{1 j}^{d e f+}, v_{2 j}^{d e f+}, \ldots, v_{n j}^{d e f+}\right\}$

$V_{j}^{-}=\left\{\left(\min v_{i j}^{d e f}, i \in G\right),\left(\max v_{i j}^{d e f}, i \in G^{-}\right), j=1, \ldots, m\right\}=\left\{v_{1 j}^{d e f-}, v_{2 j}^{d e f-}, \ldots, v_{n j}^{d e f-}\right\}$

$G^{+}$- benefit traits that are maximized;

$G^{-}$- cost traits that are minimized.

7) The distance between each candidate, positive, and negative ideal solution is:

$S_{j}^{+}=\sqrt{\sum_{i=1}^{n}\left(v_{j}^{d e f}-v_{j}^{d e f+}\right)^{2}}, 1 \leq j \leq m$

$S_{j}^{-}=\sqrt{\sum_{i=1}^{n}\left(v_{j}^{d e f}-v_{j}^{d e f-}\right)^{2}}, 1 \leq j \leq m$

8) The value of the relative degree of closeness to ideal solutions for each candidate is:

$Q_{j}^{*}=S_{j}^{-} /\left(S_{j}^{+}+S_{j}^{-}\right)^{,} 0 \leq Q_{j}^{*} \leq 1$

9) The candidates are ranked. The best solution is the candidate that has the largest value of $Q_{j}^{*}$. 


\section{Results}

\section{1. Model for Selection Candidates}

The traits' weights was carried out by fuzzyDEMATEL method as follows:

1) The comparison of influence between traits was carried out by 10 helicopter pilots (each group respectively) in form of linguistic variables. The influences between traits are the following: no influence, small influence, medium influence, high influence and very high influence. There is no influence of the trait on itself. The values of influence expressed by linguistic variables and triangular sets are shown in Figure 2 and in Table 1.

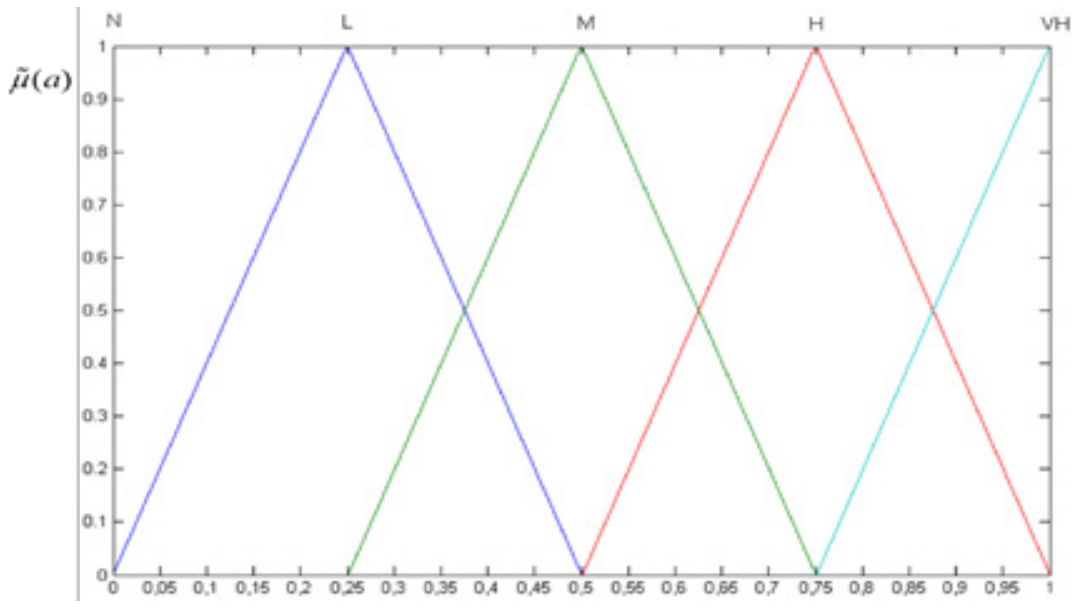

Fig. 2.

Triangular Fuzzy Set for Linguistic Variables of Influence

Table 1

DEMATEL Causal Influence Linguistic Variables and Triangular Fuzzy Set Values

\begin{tabular}{|l|l|}
\hline Linguistic Variable of Influence & Triangular Fuzzy Set \\
\hline No $(\mathrm{N})$ & $(0,0,0)$ \\
\hline Low $(\mathrm{L})$ & $(0,0.25,0.5)$ \\
\hline Medium $(\mathrm{M})$ & $(0.25,0.5,0.75)$ \\
\hline High $(\mathrm{H})$ & $(0,5,0.75,1)$ \\
\hline Very high $(\mathrm{VH})$ & $(0.75,1,1)$ \\
\hline
\end{tabular}

2) Transformation in the triangular fuzzy sets (based on Table 1) is carried out. The average fuzzy set matrix of the influence between traits $\tilde{A}$ was obtained using formula 10 .
3) The normalized direct-relation matrix $\tilde{X}$ and the total relation matrix $\tilde{T}$ were obtained using formula 11 and 12 respectively. 
4) Defuzzificated total relation matrix was obtained using formula 9 and weights of traits were obtained using formula
13-16 and model for selection of each group of helicopter pilots was formed (Figure 3 and Table 2).

Table 2

The Traits' Weights for Selection Helicopter-pilots according to their Mission

\begin{tabular}{|c|c|c|c|c|c|c|c|c|c|c|c|c|c|}
\hline \multirow[b]{2}{*}{ Traits } & \multirow{2}{*}{$\begin{array}{l}\text { Ben. } \\
\text { cost }\end{array}$} & \multicolumn{4}{|c|}{ Commercial } & \multicolumn{4}{|c|}{ Military } & \multicolumn{4}{|c|}{ Police } \\
\hline & & $D_{i}$ & $R_{j}$ & $w_{i}$ & $W_{i}$ & $D_{i}$ & $R_{j}$ & $w_{i}$ & $W_{i}$ & $D_{i}$ & $R_{j}$ & $w_{i}$ & $W_{i}$ \\
\hline ambitious & ben & 3.529 & 3.666 & 7.196 & 0.030 & 2.821 & 3.185 & 6.017 & 0.032 & 11.778 & 11.695 & 23.473 & 0.046 \\
\hline hardworking & ben & 4.146 & 4.319 & 8.467 & 0.035 & 5.202 & 5.284 & 10.486 & 0.056 & 10.976 & 10.422 & 21.405 & 0.042 \\
\hline sociable & ben & 3.975 & 4.198 & 8.176 & 0.034 & 1.467 & 3.064 & 4.804 & 0.025 & 7.612 & 7.366 & 14.980 & 0.029 \\
\hline witty & ben & 2.036 & 3.062 & 5.200 & 0.021 & 1.594 & 1.994 & 3.610 & 0.019 & 6.727 & 6.533 & 13.262 & 0.026 \\
\hline emotional & ben & 0.947 & 1.867 & 2.961 & 0.012 & 1.463 & 1.143 & 2.626 & 0.014 & 5.174 & 4.484 & 9.682 & 0.019 \\
\hline impulsive & $\cos$ & 3.042 & 3.485 & 6.542 & 0.027 & 1.673 & 1.811 & 3.487 & 0.018 & 5.696 & 6.212 & 11.919 & 0.023 \\
\hline creative & ben & 3.551 & 3.135 & 6.700 & 0.028 & 3.359 & 3.605 & 6.968 & 0.037 & 10.321 & 10.470 & 20.792 & 0.040 \\
\hline tense & $\cos$ & 6.774 & 6.027 & 12.823 & 0.053 & 5.354 & 4.799 & 10.168 & 0.054 & 9.470 & 11.969 & 21.584 & 0.042 \\
\hline responsible & ben & 7.982 & 6.458 & 14.520 & 0.060 & 6.877 & 5.963 & 12.873 & 0.068 & 13.775 & 12.925 & 26.714 & 0.052 \\
\hline determined & ben & 6.859 & 5.773 & 12.679 & 0.052 & 6.548 & 5.601 & 12.186 & 0.065 & 13.178 & 12.741 & 25.922 & 0.050 \\
\hline careful & ben & 5.341 & 5.515 & 10.857 & 0.045 & 2.690 & 3.350 & 6.076 & 0.032 & 8.836 & 9.886 & 18.751 & 0.036 \\
\hline intelligent & ben & 4.480 & 5.076 & 9.574 & 0.040 & 3.070 & 3.166 & 6.236 & 0.033 & 9.643 & 10.530 & 20.193 & 0.039 \\
\hline permissive & ben & 0.657 & 2.174 & 3.212 & 0.013 & 0.257 & 1.210 & 1.749 & 0.009 & 3.834 & 4.049 & 7.886 & 0.015 \\
\hline obedient & ben & 3.106 & 3.186 & 6.292 & 0.026 & 1.492 & 1.571 & 3.064 & 0.016 & 6.937 & 5.648 & 12.651 & 0.025 \\
\hline righteous & ben & 4.645 & 4.837 & 9.484 & 0.039 & 1.914 & 2.008 & 3.923 & 0.021 & 9.051 & 8.455 & 17.516 & 0.034 \\
\hline practical & ben & 4.162 & 4.889 & 9.080 & 0.037 & 5.746 & 5.633 & 11.380 & 0.060 & 12.856 & 11.969 & 24.841 & 0.048 \\
\hline self - critical & ben & 5.089 & 5.649 & 10.753 & 0.044 & 3.735 & 4.128 & 7.873 & 0.042 & 11.977 & 11.459 & 23.442 & 0.046 \\
\hline self - confident & ben & 7.144 & 5.948 & 13.146 & 0.054 & 5.337 & 4.866 & 10.214 & 0.054 & 13.644 & 12.467 & 26.138 & 0.051 \\
\hline cooperative & ben & 8.077 & 6.234 & 14.428 & 0.060 & 4.860 & 4.243 & 9.124 & 0.048 & 12.477 & 12.124 & 24.603 & 0.048 \\
\hline quarrelsome & $\cos$ & 3.804 & 3.913 & 7.717 & 0.032 & 2.879 & 2.957 & 5.837 & 0.031 & 4.031 & 5.651 & 9.817 & 0.019 \\
\hline selfish & $\cos$ & 3.450 & 3.630 & 7.083 & 0.029 & 6.086 & 4.117 & 10.391 & 0.055 & 9.972 & 11.861 & 21.915 & 0.043 \\
\hline modest & ben & 1.296 & 2.284 & 3.714 & 0.015 & 1.006 & 1.549 & 2.612 & 0.014 & 4.216 & 4.019 & 8.238 & 0.016 \\
\hline patient & ben & 6.067 & 5.869 & 11.938 & 0.049 & 3.438 & 3.168 & 6.611 & 0.035 & 12.233 & 12.469 & 24.703 & 0.048 \\
\hline stubborn & $\cos$ & 1.698 & 3.223 & 5.152 & 0.021 & 2.705 & 3.314 & 6.050 & 0.032 & 7.318 & 8.373 & 15.726 & 0.031 \\
\hline persistent & ben & 7.642 & 5.942 & 13.690 & 0.057 & 5.549 & 5.267 & 10.820 & 0.057 & 13.518 & 12.748 & 26.278 & 0.051 \\
\hline efficient & ben & 6.008 & 5.275 & 11.307 & 0.047 & 2.279 & 2.867 & 5.180 & 0.027 & 11.397 & 10.675 & 22.084 & 0.043 \\
\hline brave & ben & 4.808 & 4.682 & 9.490 & 0.039 & 4.414 & 3.951 & 8.378 & 0.044 & 10.296 & 9.744 & 20.048 & 0.039 \\
\hline
\end{tabular}

The most important personality traits for commercial helicopter pilots were responsible, cooperative, persistent, self - confident, tense. The least important traits were emotional, permissive, and modest. The most important personality traits for military helicopter pilots were responsible, determined, and practical.
The least important traits were permissive, emotional, modest, obedient, impulsive, and witty. The most important personality traits for police helicopter pilots were responsible, self - confident, persistent, determined, cooperative, practical, patient. The least important traits were permissive, modest, emotional, impulsive (Table 2). 

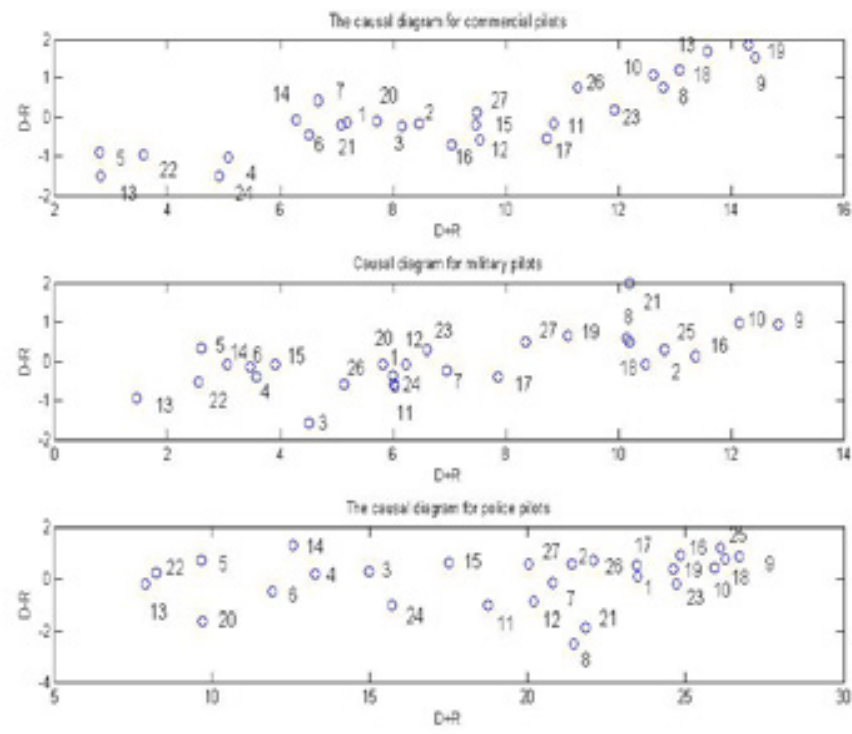

Fig. 3.

The Causal Diagram of Personality Traits

\section{Model Testing}

The model for selection helicopter pilot candidates was tested using fuzzy-TOPSIS method. At first, the individual $m(m=10)$ decision vectors, based on Likert scale value for determination quality of traits for each candidate, was formed (Figure 4 and Table 4).

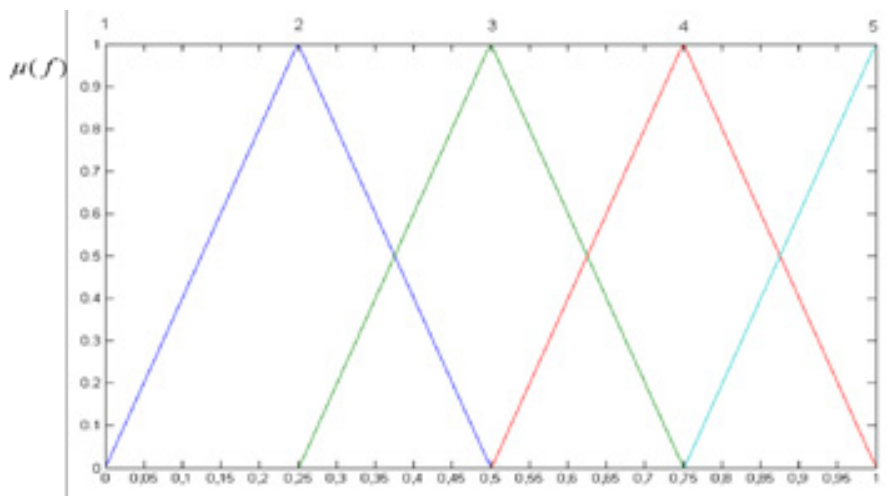

Fig. 4.

Triangular Fuzzy Set for Numerical Values of Likert Scale 
Table 3

Likert Scale (Numerical and Fuzzy Set Values)

\begin{tabular}{|c|c|l|}
\hline The Trait's Quality & Numerical Value & Fuzzy Set \\
\hline Very bad & 1 & $(0,0,0)$ \\
\hline Bad & 2 & $(0,0.25,0.5)$ \\
\hline Good & 3 & $(0.25,0.5,0.75)$ \\
\hline Very good & 4 & $(0,5,0.75,1)$ \\
\hline Excellent & 5 & $(0.75,1,1)$ \\
\hline
\end{tabular}

In the second step, the initial decision matrix was formed using the individual decision vectors. Numerical values of elements were transformed into fuzzy set.

The normalized decision matrix was obtained using formula 17 and the weighted normalized decision matrix was obtained using formula 18 . The positive and negative ideal solutions are respectively calculated using formula 19-20. The distance between each candidate, positive, and negative ideal solution is obtained using formula 21-22. According to formula 23, the values of the relative degree of closeness to ideal solutions were obtained. The value of the relative degree of closeness to ideal solutions provided ranking of all candidates (Tables 4-6).

\section{Table 4}

The Defuzzificated Weighted Normalized Decision Matrix $V_{i j}^{\text {def }}$ for Commercial Helicopter-pilots and Rank of Candidates

\begin{tabular}{|l|c|c|c|c|c|c|c|c|c|c|c|c|}
\hline \multicolumn{1}{|c|}{ Traits $\backslash$ can. } & $\mathbf{1}$ & $\mathbf{2}$ & $\mathbf{3}$ & $\mathbf{4}$ & $\mathbf{5}$ & $\mathbf{6}$ & $\mathbf{7}$ & $\mathbf{8}$ & $\mathbf{9}$ & $\mathbf{1 0}$ & $V_{j}^{+}$ & $V_{j}^{-}$ \\
\hline ambitious & 0.370 & 1.175 & 1.175 & 0.775 & 0.775 & 0.37 & 0.775 & 1.175 & 0.775 & 0.775 & 1.175 & 0.370 \\
\hline hardworking & 1.264 & 0.831 & 1.264 & 0.831 & 0.831 & 0.831 & 0.831 & 1.264 & 1.264 & 0.831 & 1.264 & 0.831 \\
\hline sociable & 0.451 & 1.437 & 0.147 & 0.147 & 1.437 & 1.437 & 0.945 & 1.437 & 0.451 & 0.451 & 1.437 & 0.147 \\
\hline witty & 0.279 & 0.583 & 0.883 & 0.583 & 0.883 & 0.883 & 0.279 & 0.091 & 0.583 & 0.279 & 0.883 & 0.091 \\
\hline emotional & 0.616 & 0.197 & 0.065 & 0.065 & 0.197 & 0.197 & 0.616 & 0.065 & 0.41 & 0.197 & 0.616 & 0.065 \\
\hline impulsive & 1.153 & 0.185 & 1.727 & 0.555 & 0.185 & 0.555 & 0 & 0.555 & 0 & 0 & 0 & 1.727 \\
\hline creative & 1.132 & 0.745 & 0.355 & 0.745 & 0.355 & 1.132 & 1.132 & 1.132 & 0.116 & 0.355 & 1.132 & 0.116 \\
\hline tense & 3.281 & 0 & 1.196 & 1.196 & 0 & 1.196 & 0 & 0 & 1.196 & 0 & 0 & 3.281 \\
\hline responsible & 1.905 & 1.905 & 1.905 & 1.905 & 1.905 & 1.905 & 1.241 & 1.905 & 1.905 & 1.905 & 1.905 & 1.241 \\
\hline determined & 0.563 & 1.812 & 1.812 & 1.812 & 1.186 & 1.812 & 1.812 & 1.812 & 1.186 & 1.186 & 1.812 & 0.563 \\
\hline careful & 0.571 & 1.810 & 0.571 & 1.195 & 1.81 & 1.195 & 1.81 & 0.571 & 1.195 & 1.195 & 1.810 & 0.571 \\
\hline intelligent & 1.059 & 1.059 & 1.599 & 1.059 & 1.059 & 1.059 & 1.059 & 1.059 & 1.059 & 1.059 & 1.599 & 1.059 \\
\hline permissive & 0.103 & 0.103 & 0 & 0.103 & 0.626 & 0.304 & 0 & 0.304 & 0.626 & 0.304 & 0.626 & 0 \\
\hline obedient & 0.136 & 0.848 & 0.409 & 0.848 & 0.848 & 0.848 & 0.409 & 0.409 & 0.848 & 0.848 & 0.848 & 0.136 \\
\hline righteous & 0.897 & 1.368 & 0.897 & 0.897 & 1.368 & 1.368 & 0.897 & 1.368 & 1.368 & 0.897 & 1.368 & 0.897 \\
\hline practical & 1.263 & 0.827 & 1.263 & 0.827 & 1.263 & 1.263 & 0.827 & 1.263 & 1.263 & 0.827 & 1.263 & 0.827 \\
\hline self- critical & 0.983 & 1.502 & 1.502 & 1.502 & 0.983 & 1.502 & 1.502 & 0.983 & 1.502 & 0.983 & 1.502 & 0.983 \\
\hline self- confident & 1.995 & 1.995 & 1.995 & 1.312 & 1.312 & 1.312 & 1.312 & 1.995 & 0.625 & 1.312 & 1.995 & 0.625 \\
\hline cooperative & 0.671 & 2.15 & 1.41 & 1.41 & 2.15 & 1.41 & 2.15 & 2.15 & 2.15 & 1.41 & 2.15 & 0.671 \\
\hline quarrelsome & 0.446 & 0 & 1.265 & 1.265 & 0 & 1.265 & 0 & 0.446 & 0 & 0.446 & 0 & 1.265 \\
\hline
\end{tabular}




\begin{tabular}{|l|c|c|c|c|c|c|c|c|c|c|c|c|}
\hline selfish & 0 & 0 & 1.018 & 1.018 & 0 & 0.356 & 0 & 0.356 & 1.018 & 1.018 & 0 & 1.018 \\
\hline modest & 0.739 & 0.236 & 0.078 & 0.236 & 0.492 & 0.236 & 0.492 & 0 & 0.492 & 0.492 & 0.739 & 0 \\
\hline patient & 0.672 & 1.403 & 2.116 & 1.403 & 0.672 & 0.672 & 2.116 & 1.403 & 0.672 & 1.403 & 2.116 & 0.672 \\
\hline stubborn & 0.826 & 0.134 & 0.826 & 0.399 & 0.134 & 0.399 & 0.826 & 0.826 & 0 & 0.134 & 0 & 0.826 \\
\hline persistent & 2 & 2 & 2 & 1.311 & 1.311 & 2 & 1.311 & 2 & 1.311 & 1.311 & 2 & 1.311 \\
\hline efficient & 0.189 & 1.216 & 0.58 & 1.849 & 1.216 & 1.849 & 1.849 & 1.849 & 0.58 & 1.216 & 1.849 & 0.189 \\
\hline brave & 1.368 & 1.368 & 1.368 & 0.897 & 0.897 & 1.368 & 0.897 & 1.368 & 0.897 & 0.897 & 1.368 & 0.897 \\
\hline \multicolumn{1}{|c|}{$Q_{j}^{*}$} & 0,416 & 0,775 & 0,499 & 0,496 & 0,683 & 0,596 & 0,692 & 0,691 & 0,510 & 0,565 & $/$ & $/$ \\
\hline \multicolumn{1}{|c|}{ Rank } & 10 & 1 & 8 & 9 & 4 & 5 & 2 & 3 & 7 & 6 & $/$ & $/$ \\
\hline
\end{tabular}

The most important traits of the most successful commercial helicopter pilot were self - confident, responsible, determined, careful. The most important traits of the least successful commercial helicopter pilot were tense, responsible and self - confident.

\section{Table 5}

The Defuzzificated Weighted Normalized Decision Matrix $V_{i j}^{\text {def }}$ for Military Helicopter Pilots and Rank of Candidates

\begin{tabular}{|c|c|c|c|c|c|c|c|c|c|c|c|c|}
\hline Traits\can. & 1 & 2 & 3 & 4 & 5 & 6 & 7 & 8 & 9 & 10 & $V_{j}^{+}$ & $V_{j}^{-}$ \\
\hline ambitious & 0.393 & 1.248 & 1.248 & 0.823 & 0.823 & 0.393 & 0.823 & 1.248 & 0.823 & 0.823 & 1.248 & 0.393 \\
\hline hardworking & 2.007 & 1.319 & 2.007 & 1.319 & 1.319 & 1.319 & 1.319 & 2.007 & 2.007 & 1.319 & 2.007 & 1.319 \\
\hline sociable & 0.337 & 1.075 & 0.110 & 0.110 & 1.075 & 1.075 & 0.708 & 1.075 & 0.337 & 0.337 & 1.075 & 0.110 \\
\hline witty & 0.254 & 0.531 & 0.804 & 0.531 & 0.804 & 0.804 & 0.254 & 0.083 & 0.531 & 0.254 & 0.804 & 0.083 \\
\hline emotional & 0.714 & 0.228 & 0.075 & 0.075 & 0.228 & 0.228 & 0.714 & 0.075 & 0.475 & 0.228 & 0.714 & 0.075 \\
\hline impulsive & 0.789 & 0.126 & 1.181 & 0.380 & 0.126 & 0.380 & 0.000 & 0.380 & 0.000 & 0.000 & 0.000 & 1.181 \\
\hline creative & 1.492 & 0.982 & 0.468 & 0.982 & 0.468 & 1.492 & 1.492 & 1.492 & 0.153 & 0.468 & 1.492 & 0.153 \\
\hline tense & 3.335 & 0.000 & 1.215 & 1.215 & 0.000 & 1.215 & 0.000 & 0.000 & 1.215 & 0.000 & 0.000 & 3.335 \\
\hline responsible & 2.166 & 2.166 & 2.166 & 2.166 & 2.166 & 2.166 & 1.410 & 2.166 & 2.166 & 2.166 & 2.166 & 1.410 \\
\hline determined & 0.700 & 2.249 & 2.249 & 2.249 & 1.472 & 2.249 & 2.249 & 2.249 & 1.472 & 1.472 & 2.249 & 0.700 \\
\hline careful & 0.408 & 1.295 & 0.408 & 0.855 & 1.295 & 0.855 & 1.295 & 0.408 & 0.855 & 0.855 & 1.295 & 0.408 \\
\hline intelligent & 0.875 & 0.875 & 1.321 & 0.875 & 0.875 & 0.875 & 0.875 & 0.875 & 0.875 & 0.875 & 1.321 & 0.875 \\
\hline permissive & 0.073 & 0.073 & 0.000 & 0.073 & 0.447 & 0.217 & 0.000 & 0.217 & 0.447 & 0.217 & 0.447 & 0.000 \\
\hline obedient & 0.085 & 0.530 & 0.255 & 0.530 & 0.530 & 0.530 & 0.255 & 0.255 & 0.530 & 0.530 & 0.530 & 0.085 \\
\hline righteous & 0.478 & 0.729 & 0.478 & 0.478 & 0.729 & 0.729 & 0.478 & 0.729 & 0.729 & 0.478 & 0.729 & 0.478 \\
\hline practical & 2.059 & 1.347 & 2.059 & 1.347 & 2.059 & 2.059 & 1.347 & 2.059 & 2.059 & 1.347 & 2.059 & 1.347 \\
\hline self - critical & 0.932 & 1.424 & 1.424 & 1.424 & 0.932 & 1.424 & 1.424 & 0.932 & 1.424 & 0.932 & 1.424 & 0.932 \\
\hline self - confident & 2.000 & 2.000 & 2.000 & 1.314 & 1.314 & 1.314 & 1.314 & 2.000 & 0.626 & 1.314 & 2.000 & 0.626 \\
\hline cooperative & 0.541 & 1.733 & 1.136 & 1.136 & 1.733 & 1.136 & 1.733 & 1.733 & 1.733 & 1.136 & 1.733 & 0.541 \\
\hline quarrelsome & 0.431 & 0.000 & 1.223 & 1.223 & 0.000 & 1.223 & 0.000 & 0.431 & 0.000 & 0.431 & 0.000 & 1.223 \\
\hline selfish & 0.000 & 0.000 & 1.932 & 1.932 & 0.000 & 0.675 & 0.000 & 0.675 & 1.932 & 1.932 & 0.000 & 1.932 \\
\hline modest & 0.681 & 0.218 & 0.072 & 0.218 & 0.454 & 0.218 & 0.454 & 0.000 & 0.454 & 0.454 & 0.681 & 0.000 \\
\hline patient & 0.481 & 1.003 & 1.512 & 1.003 & 0.481 & 0.481 & 1.512 & 1.003 & 0.481 & 1.003 & 1.512 & 0.481 \\
\hline stubborn & 1.260 & 0.204 & 1.260 & 0.609 & 0.204 & 0.609 & 1.260 & 1.260 & 0.000 & 0.204 & 0.000 & 1.260 \\
\hline
\end{tabular}




\begin{tabular}{|l|c|c|c|c|c|c|c|c|c|c|c|c|}
\hline persistent & 2.011 & 2.011 & 2.011 & 1.319 & 1.319 & 2.011 & 1.319 & 2.011 & 1.319 & 1.319 & 2.011 & 1.319 \\
\hline efficient & 0.110 & 0.710 & 0.338 & 1.079 & 0.710 & 1.079 & 1.079 & 1.079 & 0.338 & 0.710 & 1.079 & 0.110 \\
\hline brave & 1.557 & 1.557 & 1.557 & 1.021 & 1.021 & 1.557 & 1.021 & 1.557 & 1.021 & 1.021 & 1.557 & 1.021 \\
\hline \multicolumn{1}{|c}{$Q_{j}^{*}$} & 0,346 & 0,774 & 0,490 & 0,533 & 0,680 & 0,588 & 0,718 & 0,687 & 0,533 & 0,609 & $/$ & $/$ \\
\hline \multicolumn{1}{|c|}{ Rank } & 10 & 1 & 9 & 7 & 4 & 6 & 2 & 3 & 8 & 5 & $/$ & $/$ \\
\hline
\end{tabular}

The most important traits of the most successful military helicopter pilot were determined, responsible, self - confident, cooperative and brave. The most important traits of the least successful military helicopter pilot were tense, responsible, practical, persistent, hardworking, self confident, brave, creative and stubborn.

\section{Table 6}

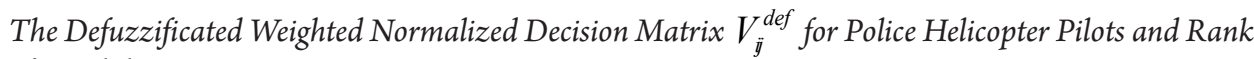
of Candidates

\begin{tabular}{|c|c|c|c|c|c|c|c|c|c|c|c|c|}
\hline Traits $\backslash$ can. & 1 & 2 & 3 & 4 & 5 & 6 & 7 & 8 & 9 & 10 & $V_{j}^{+}$ & $V_{j}^{-}$ \\
\hline ambitious & 0.563 & 1.786 & 1.786 & 1.178 & 1.178 & 0.563 & 1.178 & 1.786 & 1.178 & 1.178 & 1.786 & 0.563 \\
\hline hardworking & 1.503 & 0.987 & 1.503 & 0.987 & 0.987 & 0.987 & 0.987 & 1.503 & 1.503 & 0.987 & 1.503 & 0.987 \\
\hline sociable & 0.386 & 1.230 & 0.126 & 0.126 & 1.230 & 1.230 & 0.809 & 1.230 & 0.386 & 0.386 & 1.230 & 0.126 \\
\hline witty & 0.342 & 0.715 & 1.084 & 0.715 & 1.084 & 1.084 & 0.342 & 0.112 & 0.715 & 0.342 & 1.084 & 0.112 \\
\hline emotional & 0.966 & 0.308 & 0.102 & 0.102 & 0.308 & 0.308 & 0.966 & 0.102 & 0.642 & 0.308 & 0.966 & 0.102 \\
\hline impulsive & 0.990 & 0.158 & 1.481 & 0.476 & 0.158 & 0.476 & 0.000 & 0.476 & 0.000 & 0.000 & 0.000 & 1.481 \\
\hline creative & 1.633 & 1.075 & 0.512 & 1.075 & 0.512 & 1.633 & 1.633 & 1.633 & 0.167 & 0.512 & 1.633 & 0.167 \\
\hline tense & 2.597 & 0.000 & 0.946 & 0.946 & 0.000 & 0.946 & 0.000 & 0.000 & 0.946 & 0.000 & 0.000 & 2.597 \\
\hline responsible & 1.649 & 1.649 & 1.649 & 1.649 & 1.649 & 1.649 & 1.073 & 1.649 & 1.649 & 1.649 & 1.649 & 1.073 \\
\hline determined & 0.546 & 1.755 & 1.755 & 1.755 & 1.149 & 1.755 & 1.755 & 1.755 & 1.149 & 1.149 & 1.755 & 0.546 \\
\hline careful & 0.462 & 1.466 & 0.462 & 0.968 & 1.466 & 0.968 & 1.466 & 0.462 & 0.968 & 0.968 & 1.466 & 0.462 \\
\hline intelligent & 1.039 & 1.039 & 1.569 & 1.039 & 1.039 & 1.039 & 1.039 & 1.039 & 1.039 & 1.039 & 1.569 & 1.039 \\
\hline permissive & 0.121 & 0.121 & 0.000 & 0.121 & 0.739 & 0.359 & 0.000 & 0.359 & 0.739 & 0.359 & 0.739 & 0.000 \\
\hline obedient & 0.129 & 0.802 & 0.387 & 0.802 & 0.802 & 0.802 & 0.387 & 0.387 & 0.802 & 0.802 & 0.802 & 0.129 \\
\hline righteous & 0.783 & 1.194 & 0.783 & 0.783 & 1.194 & 1.194 & 0.783 & 1.194 & 1.194 & 0.783 & 1.194 & 0.783 \\
\hline practical & 1.648 & 1.079 & 1.648 & 1.079 & 1.648 & 1.648 & 1.079 & 1.648 & 1.648 & 1.079 & 1.648 & 1.079 \\
\hline self - critical & 1.018 & 1.555 & 1.555 & 1.555 & 1.018 & 1.555 & 1.555 & 1.018 & 1.555 & 1.018 & 1.555 & 1.018 \\
\hline self - confident & 1.877 & 1.877 & 1.877 & 1.234 & 1.234 & 1.234 & 1.234 & 1.877 & 0.588 & 1.234 & 1.877 & 0.588 \\
\hline cooperative & 0.535 & 1.714 & 1.124 & 1.124 & 1.714 & 1.124 & 1.714 & 1.714 & 1.714 & 1.124 & 1.714 & 0.535 \\
\hline quarrelsome & 0.266 & 0.000 & 0.754 & 0.754 & 0.000 & 0.754 & 0.000 & 0.266 & 0.000 & 0.266 & 0.000 & 0.754 \\
\hline selfish & 0.000 & 0.000 & 1.495 & 1.495 & 0.000 & 0.522 & 0.000 & 0.522 & 1.495 & 1.495 & 0.000 & 1.495 \\
\hline modest & 0.788 & 0.252 & 0.084 & 0.252 & 0.525 & 0.252 & 0.525 & 0.000 & 0.525 & 0.525 & 0.788 & 0.000 \\
\hline patient & 0.659 & 1.375 & 2.073 & 1.375 & 0.659 & 0.659 & 2.073 & 1.375 & 0.659 & 1.375 & 2.073 & 0.659 \\
\hline stubborn & 1.201 & 0.194 & 1.201 & 0.580 & 0.194 & 0.580 & 1.201 & 1.201 & 0.000 & 0.194 & 0.000 & 1.201 \\
\hline persistent & 1.792 & 1.792 & 1.792 & 1.175 & 1.175 & 1.792 & 1.175 & 1.792 & 1.175 & 1.175 & 1.792 & 1.175 \\
\hline efficient & 0.173 & 1.110 & 0.529 & 1.688 & 1.110 & 1.688 & 1.688 & 1.688 & 0.529 & 1.110 & 1.688 & 0.173 \\
\hline brave & 1.367 & 1.367 & 1.367 & 0.896 & 0.896 & 1.367 & 0.896 & 1.367 & 0.896 & 0.896 & 1.367 & 0.896 \\
\hline$Q_{j}^{*}$ & 0.399 & 0.734 & 0.486 & 0.514 & 0.639 & 0.587 & 0.675 & 0.649 & 0.497 & 0.549 & 1 & 1 \\
\hline Rank & 10 & 1 & 9 & 7 & 4 & 5 & 2 & 3 & 8 & 6 & 1 & I \\
\hline
\end{tabular}


The most important traits of the most successful police helicopter pilot were self confident, persistent, ambitious, determined, cooperative, responsible, self - critical and careful. The most important traits of the least successful police helicopter pilot were tense, self - confident, persistent, responsible, practical, creative and hardworking. It might be concluded that purposed model really discriminate successful candidates according to the mission type.

\section{Discussion}

Obtained results showed, from the perspective of experienced and successful helicopter pilots, that there are 27 personality traits in common for all successful helicopter pilots. Among 27 selected, five traits showed negative effects: impulsive, tense, quarrelsome, selfish and stubborn. The presence of these characteristics is very harmful: the larger percentage of helicopter pilots possess them, the less he/ she will be successful and will represent potential flight safety risk. It is worth mentioning that three of them belong to the field of interpersonal relationships skills and managerial skills, team leadership and team-building. High presence of these traits leads to the conflicts and negative atmosphere and bad communication among crew members, which might have direct impact on efficiency of mission and safety of flight, but also phenomena such as burnout syndrome, absenteeism and drop out of the job or organization. Some of previous research also registered some negative traits like dependent and avoidant personality traits (Ganesh \& Joseph, 2005), excessive aggressiveness, impulsivity, decreased tolerance for tension/stress, difficulty with interpersonal relationships (Voge, 1989), as great potential for risky behavior and unsuccessful task performance. Ranking of these traits is also different according to the mission. In the commercial sample, a highly valued negative trait was tense (Table 2): successful commercial helicopter pilot must not be tense and under pressure if he/ she wants to get a job and make a positive impression on the employer. The trait impulsive in military and police samples was the least important of all negative traits. Explanation is that some situations and tasks during duty calls demand extremely quick reactions, without too much thinking and hesitation, since the price can be very high. This implies the importance of the use of negative attributes/characteristics/traits in the process of selection and assessment, as it was mentioned by some researchers (Foushee \& Helmreich, 1988; Donovan et al., 2003) especially when it comes to the faking behavior, when applicants try to minimize their negative attributes. Information about these traits can have select-out value, and it is strongly recommended to pay attention to those candidates who have high scores on cost personality traits. 


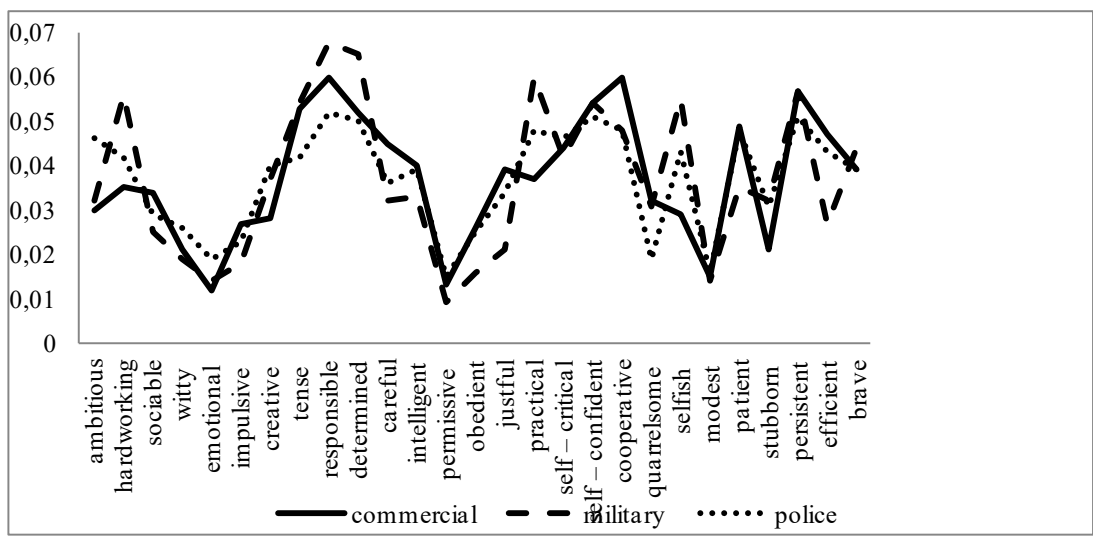

Fig. 5.

Required Traits for Successful Helicopter Pilot According to Type of Mission

General profile of successful helicopter pilot (no matter the nature of the mission) characterize high levels of responsibility, determination, persistence; moderate level of self - criticism, intelligence and low level of emotionality, permissiveness and modesty (Figure 5). All helicopter pilots, no matter the mission type, emphasize the importance of responsibility as the most important trait for becoming successful (Table 2). Safety of flight, tasks performance, transport of people and goods seem to be their main mission. The least important traits for all groups of pilots were emotional, permissive, modest, witty and obedient. It might be said that "expressive" and "agreeable" traits which are highly socially valued are missing part in personality of successful helicopter pilots, generally. This is a very important part, since even technical jobs, such as those in aviation, have a social element that is important for organizational success (especially in civil and commercial aviation).

When it comes to the differences, successful commercial pilots, in comparison with other two groups, must be more careful, righteous, cooperative and efficient; successful military pilots, in comparison with other two groups must be more hardworking, determined, less selfish, less self - confident, less cooperative, less patient, less stubborn and less efficient. Successful police pilots, in comparison with other two groups, must be more ambitious and patient and less relaxed and more pacific (Table 2). These findings are in accordance with those of Jenkins et al. (1971) of correlation of achievement striving. Achievement striving is related to positive performances, including scientific and academic achievements. Our findings are opposite to the results of (Chidester, 1990) that impatience and irritability are not correlated with performance in pilots. Results are not completely in accordance with those of Dickens (2021) that commercial rotary-wing pilots tend to be sociable, assertive, energetic, cooperative, empathetic, warm, organized, methodical and self-disciplined. It seems that commercial helicopter pilots, although more directed toward other people than other two groups of pilots, in a sense of communication and coordination, are not 
so expressive about their own feelings, and are not tending to be in close relationships with other people. They are more on a polite distance, which is in accordance with findings of Geist and Boyd (1980) found in military helicopter pilots' sample and traits of positive instrumentality (Chidester et al., 1991). Chaturvedula and Joseph (2007) also reported higher levels of extraversion, openness and conscientiousness and lower levels of neuroticism among helicopter pilots, which is consistent with our data.

We can see that the importance of communication skills and expressiveness traits are of high importance for commercial pilots especially, and it might be presumed that that fact is the direct consequence of the job fitness. Sociability, fairness, team working and agreeableness are highly relevant if the pilots want to get or keep the job. On the other hand, military pilots must work hard to get success and be determined and quick. They are aware of their own dependence on others, which make them more dependent and less self - confident and at the same time less efficient, since they are always under pressure of protecting others and of dependence of someone else's life on their own acts and decisions, especially when it comes to use of weapons, which is consistent with results of Chidester et al. (1991) that military flight experience was positively related to communication and coordination, but unrelated to command responsibility and Grice and Katz (2006) that military helicopter pilots had low results on vulnerability, aesthetics, and compliance, and scored in the high range in competence and achievement striving (Grice $\&$ Katz, 2007). Police pilots are somewhere in between: he/she wants to be promoted and work efficiently, he/she is always on standby, but also has to possess some social skills like patience, cooperativeness and peacefulness, although to a lesser degree than commercial pilots. Also, they are not as brave and hardworking oriented as military helicopter pilots.

\section{Conclusion}

Findings from organizational psychology suggest that personality traits could be predictive of vocational success, performance and productivity. Predicting a job-fit personthrough personality testing is especially important when screening applicants for occupations that are high risk and involve working with the public, such as pilots. Employers have to ensure that applicants hired for this position will not only have the needed mental and physical abilities, but also the personality traits that will help them be successful. Previous failures in the process of finding links between personality and performance were due to a combination of inadequate statistical modelling, premature performance evaluation, small samples, not paying attention to moderator variables and/ or the reliance on data gathered in contrived as opposed to realistic situations. Multiple criteria model and its results proposed in this paper might be a useful tool of assessment and selection, especially in the small and very highly selected sample. Investigation of some other personality concepts and their relationships with personality traits and mission types, like stress coping strategies and crew interaction styles might be also the right choice, since it is obvious that pilot lacks expressive traits which might be also crucial for understanding the personality characteristics of pilots who crashed or risk assessment and stress management themes and understanding how personality traits can influence decision-making and enhance safety in the flight deck. 


\section{References}

Ashman, A.; Tefler, R. 1983. Personality profiles of pilots, Aviation, Space, and Environmental Medicine 54: 940-943.

Baykasoğlu, A.; Gölcük, İ. 2017. Development of an interval type-2 fuzzy sets based hierarchical MADM model by combining DEMATEL and TOPSIS, Expert Systems with Applications 70: 37-51.

Besco, R. 1994. Pilot personality testing and the emperor's new clothes. In Ergonomics in Design, 24-29.

Boyd, J. E.; Patterson, J. C.; Thompson, B. T. 2005. Psychological test profiles of USAF pilots before training vs. type aircraft flown, Aviation, Space, and Environmental Medicine 76: 463-468.

Brodsky, S. L.; Brodsky, A. M. 1967. Hand test indicators of antisocial behavior, Journal of Projective Personality Assessment 31: 36-39.

Bubalo, T.; Rajsman, M.; Škorput, P. 2021. Analytic hierarchy process in the function of evaluation of transport service quality in Bus Company, International Journal for Traffic \& Transport Engineering 11(1): 1-16.

Chang, D. Y. 1996. Applications of the extent analysis method on fuzzy AHP, European journal of operational research 95(3): 649-655.

Chappelle, W.; Novy, P. L.; Sowin, T. W.; Thompson, W. T. 2010. NEO PI-R Normative Personality Data That Distinguish U.S. Air Force Female Pilots, Military Psychology 22(2): 158-175.

Chaturvedula, S.; Joseph, C. 2007. Dimensions of psychological well-being and personality in military aircrew: A preliminary study, Indian Journal of Aerospace Medicine 51(2): 17-27.

Chidester, T. R. 1990. Trends and individual differences in rerrponse to short-haul flight operations, Aviation, Space, and Environmental Medicine 61: 132-138.
Chidester, T.R.; Helmreich, R.L.; Gregorich, S.E.; Geis, C.E. 1991. Pilot Personality and Crew Coordination: Implications for Training and Selection, The International Journal of Aviation Psychology 1(1): 25-44.

Chou, Y. C.; Sun, C. C.; Yen, H. Y. 2012. Evaluating the criteria for human resource for science and technology (HRST) based on an integrated fuzzy AHP and fuzzy DEMATEL approach, Applied Soft Computing 12(1): 64-71.

Christen, B.R.; Moore, J. L. 1998. A descriptive analysis of "not aeronautically adaptable" dispositions in the US Navy, Aviation, Space and Environmental Medicine 69(11): 1071-1075.

Čokorilo, O.; Gvozdenović, S.; Mirosavljević, P.; Vasov, L. 2010. Multi attribute decision making: Assessing the technological and operational parameters of an aircraft, Transport 25(4): 352-356.

Devadoss, A. V.; Felix, A. A. 2013. Fuzzy DEMATEL approach to study cause and effect relationship of youth violence, International Journal of Computing Algorithm 2: 363-372.

Dickens, P. 2021. Big 5 Personality Characteristics of Rotary-Wing Aircrew. Available from Internet: $<$ Big 5 Personality Characteristics of Rotary-Wing Aircrew. pdf (multiscreensite.com)>.

Dockeray F.C.; Isaacs, S. 1921. Psychological research in aviation in Italy, France, England, and the American Expeditionary Forces, Journal of Comparative Psychology 1(2): 115-148.

Donovan, J. J.; Dwight, S. A.; Hurtz, G. M. 2003. An assessment of the prevalence, severity, and verifiability of entry level applicant faking using the randomized response technique, Human Performance 16: 81-106.

Dožić, S. 2019. Multi-criteria decision making methods: Application in the aviation industry, Journal of Air Transport Management 79: 1-22. 
Foushe, H. C.; Helmreich, R L.1988. Group interaction md flight crew performance. In Human factors in aviation, 189-227.

Fry, G. E.; Reinhardt, R. F. 1969. Personality characteristic of jet pilots as measured by the Edward Personal Preference Schedule, Aerospace Medicine 40: 484-486.

Galić, Z.; Jerneić, Ž.; Kovačić, M. P. 2012. Do applicants fake their personality questionnaire responses and how successful are their attempts? A case of military pilot cadet selection, International Journal of Selection and Assessment 20(2): 229-241.

Ganesh, D.; Joseph, C. 2005. Personality studies in aircrew: An overview, Indian Journal of Aerospace Medicine 49(1): 54-62.

Gavade, R. K. 2014. Multi-Criteria Decision Making: An overview of different selection problems and methods, International Journal of Computer Science and Information Technologies 5(4): 5643-5646.

Geist, C. R.; Boyd, S. T. 1980. Personality Characteristics of Army Helicopter Pilots, Perceptual and Motor Skills 51(1): 253-254.

Grice, R.; Katz, L. C. 2006. Personality profiles of experienced US Army aviators across mission platforms. Available from Internet: <a457567.pdf (dtic.mil)>.

Grice, R.; Katz, L. C. 2007. Personality Profiles of U.S. Army Initial Entry Rotary Wing Students Versus Career Aviators. Available from Internet: <Microsoft Word - TR 1208.doc (dtic.mil)>.

Hosseini, M. B.; Tarokh, M. J. 2013. Type-2 fuzzy set extension of DEMATEL method combined with perceptual computing for decision making, Journal of Industrial Engineering International 9(1): 1-10.

Hunter, D. R.; Burke, E. F. 1994. Predicting aircraft pilot training success: A meta-analysis of published research, The International Journal of Aviation Psychology 4(4): 297-313.

Hunter, D. R. 1989. Aviator selection. In Military personnel measurement, 129-167.

Hwang, C. L.; Yoon, K. 1981. Methods for multiple attribute decision making. In Multiple attribute decision making, 58-191.

Jenkins, C. D.; Zyzanski, S. I.; Rosenman, R. H. 1971. Progress toward validation of a computer scored test for the Type A coronary prone behavior pattern, Psychometric Medicine 33: 193-202.

Junior, F. R. L.; Osiro, L.; Carpinetti, L. C. R. 2014. A comparison between Fuzzy AHP and Fuzzy TOPSIS methods to supplier selection, Applied Soft Computing 21: 194-209.

Kahraman, C.; Onar, S. C.; Oztaysi, B. 2015. Fuzzy multicriteria decision-making: a literature review, International journal of computational intelligence systems 8(4): 637-666.

Kahraman, C.; Öztayşi, B.; Sarı, İ. U.; Turanoğlu, E. 2014. Fuzzy analytic hierarchy process with interval type-2 fuzzy sets, Knowledge-Based Systems 59: 48-57.

King, R. E.; McGlohn, S. E.; Retzlaff, P. D. 1997. Female United States Air Force pilot personality: The new right stuff, Military Medicine 162: 695-697.

King, R. E.; Retzlaff, P.D.; Barto, E. B.; Ree, M.J.; Teachout, M. S. 2012. Pilot personality and training outcomes. Available from internet: <a571477.pdf (dtic.mil)>.

King, R.E.; McGlohn, S.E.; Retzlaff, P.D. 1997. Female United States Air Force pilot personality: the new right stuff, Military Medicine 162(10): 695-697.

Lardent, Jr. C. L. 1991. Pilots who crash: personality constructs underlying accident prone behavior of fighter pilots, Multivariate Experimental Clinical Research 10: 1-25. 
Lin, R. J. 2013. Using fuzzy DEMATEL to evaluate the green supply chain management practices, Journal of Cleaner Production 40: 32-39.

Martinussen, M. 1996. Psychological measures as predictors of pilot performance: A meta-analysis, The International Journal of Aviation Psychology 6(1): 1-20.

McGlohn, S.E.; King, R.E.; Butler, J.W.; Retzlaff, P.D. 1997. Female United States Air Force (USAF) pilots: themes, challenges, and possible solutions, Aviation, Space and Environmental Medicine 68(2): 132-136.

Meško, M.; Karpljuk, D.; Meško Štok, Z.; Videmšek, M.; Bertoncel, T.; Bertoncelj, A.; Podbregar , I. 2013. Motor Abilities and Psychological Characteristics of Slovene Military Pilots, The International Journal of Aviation Psychology 23(4): 306-318.

Moghaddam, N. B.; Sahafzadeh, M.; Alavijeh, A. S.; Yousefdehi, H.; Hosseini, S. H. 2011. Strategic Environment Analysis Using DEMATEL Method through Systematic Approach, Management Science and Engineering 4(4): 95-105.

Muhammad, M. N.; Cavus, N. 2017. Fuzzy DEMATEL method for identifying LMS evaluation criteria, Procedia computer science 120: 742-749.

Novello, J. R.; Yousset, Z. I. 1974a. Psychosocial studies in general aviation: I. Personality profile of male pilots, Aerospace Medicine 45: 185-188.

Novello, J. R.; Youssef, Z. I. 1974b. Psycho-social studies in general aviation: II. Personality profile of female pilots, Aerospace Medicine 45: 660-663.

Rajati, M. R.; Mendel, J. M. 2013. On advanced computing with words using the generalized extension principle for type-1 fuzzy sets, IEEE Transactions on Fuzzy Systems 22(5): 1245-1261.
Retzlaff, P. D.; Gibertini, M. 1987. Air Force pilot personality: Hard data on the right stuff, Multivariate Behavioral Research 22(4): 383-389.

Rippon, T. S.; Manuel, E.G. 1918. The report on the essential characteristics of successful and unsuccessful aviators with special reference to temperament, The Lancet 192(4961): 411-415.

Sangaiah, A. K.; Subramaniam, P. R.; Zheng, X. 2015. A combined fuzzy DEMATEL and fuzzy TOPSIS approach for evaluating GSD project outcome factors, Neural Computing and Applications 26(5): 1025-1040.

Shih, H. S. 2008. Incremental analysis for MCDM with an application to group TOPSIS, European Journal of Operational Research 186(2): 720-734.

Tadić, S.; Zečević, S.; Krstić, M. 2015. Ranking of logistics system scenarios using combined fuzzy ahpvikor model, International Journal for Traffic and Transport Engineering 5(1): 54-63.

Velasquez, M.; Hester, P. T. 2013. An analysis of multicriteria decision making methods, International journal of operations research 10(2): 56-66.

Voge, V.M. 1989. Failing aviator syndrome: a case history, Aviation Space and Environmental Medicine 60(7): 89-91.

Wakcher, S.; Cross, K.; Blackman, M. C. 2003. Personality Comparison of Airline Pilot Incumbents, Applicants, and the General Population Norms on the 16PF, Psychological Reports 92(3): 773-780.

Wu, W. W.; Lee, Y. T. 2007. Developing global managers'competencies using the fuzzy DEMATEL method, Expert systems with applications 32(2): 499-507. 